\title{
Kienböck's Disease; the Length of Capitate and Third Metacarpal Bones
}

\author{
Davod Jafari, ${ }^{1}$ Hooman Shariatzadeh, ${ }^{1}$ and Ali Ajvadi ${ }^{1,}{ }^{*}$ \\ ${ }^{1}$ Bone and Joint Reconstruction Research Center, Shafa Orthopedic Hospital, Iran University of Medical Sciences, Tehran, IR Iran \\ "Corresponding author: Ali Ajvadi, Bone and Joint Research Center, Shafa Orthopedic Hospital, Iran University of Medical Sciences, Tehran, IR Iran. Tel: +98-2133542022, E-mail: \\ aliajvadi@gmail.com
}

Received 2016 February 28; Revised 2016 April 26; Accepted 2016 July 08.

\begin{abstract}
Background: The relationship between negative ulnar variance and Kienböck's disease is unknown and does not justify all of the cases. The present study planed the hypothesis that maybe the pressure from distal structures to the lunate bone plays a role in the etiology.

Objectives: The current study aimed to investigate the possibility of a relationship between an increased length of the third metacarpal and the capitate with Kienböck's disease .

Methods: The study compared the wrist posteroanterior (PA) X-ray images of 105 healthy individuals with those of 91 patients with Kienböck's disease. Meticulous measurement criteria were defined in the present study to measure the third metacarpal and the capitate lengths. These lengths along with ulnar variance were measured on each X-ray. The Lichtman classification was used for staging. A new index, named capitate-index, was defined due to the linear relationship between the capitate and the third metacarpal lengths.

Results: Comparing the two groups, no meaningful difference was observed between the capitate and third metacarpal bone lengths in patients and the control group. Also, there was no significant difference in the capitate-index (capitate length/3rd metacarpal length) between the groups. Furthermore, no differences were observed comparing the patients with ulnar variance $\geqq 0$ and patients with ulnar variance $<0$ to the control group regarding the above parameters. The only significant difference was a higher negative ulnar variance among the patients with Kienböck's disease .

Conclusions: Based on the above-mentioned findings, the existence of a relationship between the third metacarpal and the capitate lengths and the Kienböck's disease is unlikely.
\end{abstract}

Keywords: Kienböck's Disease, Lunate Bone, Capitate Bone, Metacarpal Bones

\section{Background}

Kienböck's disease (KD) is the lunate bone osteonecrosis that causes complete degeneration of the bone in the late stages leading to wrist osteoarthritis. Despite various surgical treatments performed on patients, studies could not find significant difference among these methods (1), showing that the etiology of KD is still unidentified.

Among the most important reasons discussed in the literature so far, negative ulnar variance, arterial ischemia, trauma and occupational factors are considered as the etiology of KD more than others (2). Nevertheless, none of these factors is proven or rejected. Despite the popularity of the lunate overload theory caused by the negative ulnar variance, some cases cannot be explained by this theory. Two meta-analyses conducted in this field showed that there is not enough evidence to prove such a relationship $(3,4)$.

\section{Objectives}

In an attempt to find another factor to be both in line with the lunate overload theory and justify zero or positive ulnar variance cases, the authors investigated the possibility of a relationship between the third metacarpal and capitate lengths and KD.

\section{Methods}

The study was approved by the ethical committee of Iran University of Medical Sciences, and the X-rays of 111 patients with KD, underwent surgery in Shafa orthopedic hospital from 2009 to 2015 were reviewed. The diagnosis was made according to the X-ray and magnetic resonance imaging (MRI) findings. Among the patients, 91 cases with established KD and a good quality standard posteroanterior (PA) X-ray images were included in the study.

The Lichtman classification was used for staging (5). Age matched, normal x-rays of 105 volunteers referring to 
outpatient clinic of Shafa Hospital were used as the control group. Descriptive statistics of the patients and the control group are presented in Table 1.

According to the hospital protocol, the wrist PAX-ray is performed by Schreibman method (6) with a 90 degrees abduction of the shoulders, 90 degrees flexion of the elbow, and a neutral position of the forearm.

Magnifier of the picture archiving and communication system (PACS) is applied to find the bone markers more accurately.

For a few patients, the radiography had been taken as plane X-ray. For these cases a $2.5^{*}$ loupe magnifying glass and a caliper with $0.1 \mathrm{~mm}$ accuracy was used to measure bone markers. To make sure that the measurements had identical calibration in both plane X-ray and PACS system measurements were compared in 20 patients X-rayed both systems. A constant difference was observed between the two methods that decreased to $\pm 0.15 \mathrm{~mm}$ with acceptable intra-observer reliability through defining a corrective coefficient in the computer software.

\subsection{Bony Landmarks}

Three measurements were performed on each X-ray; the capitate and the third metacarpal lengths along their long axes and ulnar variance measurement through Palmer method (7).

While measuring the third metacarpal and the capitate lengths, authors noticed variations in the X-ray of distal pole of the capitate and the proximal base of the third metacarpal which could disturb the measurements up to 1 $\mathrm{mm}$ in each region (Figure 1). Therefore, the intersection between the capitate and the metacarpal axes were used with the line that was farther from the carpometacarpal joint.

No exact landmark had been specified for these regions in the articles which measured the third metacarpal and capitate lengths (8-13). Therefore, a pilot study was conducted to define a bone marker with acceptable intraobserver reliability.

As shown in Figure 1, the third metacarpal and capitate anterior and posterior edges do not overlap most of the times and resemble two separate parallel lines. Of these lines, two central lines, closer to the carpometacarpal (CMC) joint, do not have clear-cut edges but farther lines are almost always clear. The intersection of the two bones axes with the line farther from the joint was determined as a reference point.

Measurements were performed twice by senior author on 20 X-rays (10 patients with Kienböck's disease and 10 normal subjects) at intervals of one week to make sure about the intra-observer reliability of the reference points.
Figure 1. Reference Points to Measure Capitate and the 3rd Metacarpal Length

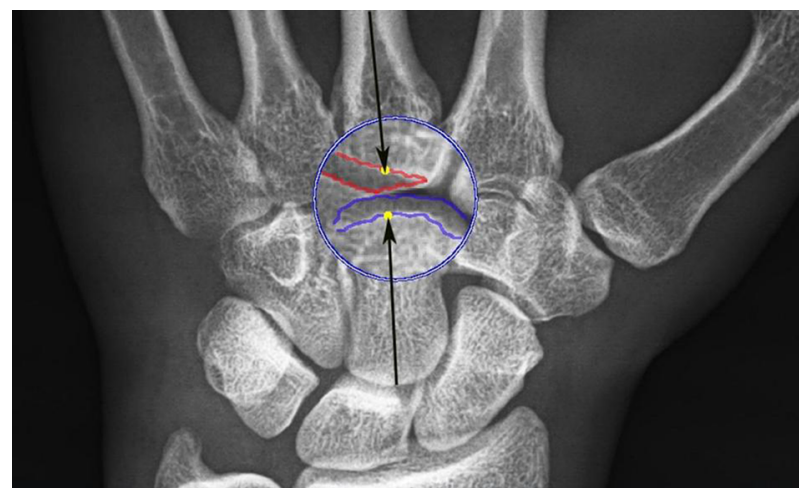

Near carpometacarpal joint in each bone there are two parallel lines resulted from anterior and posterior edges. The intersection between the capitate and the metacarpal axes with the line that was farther from the carpometacarpal joint was selected.

The variation between the two measurements was \pm 0.16 $\mathrm{mm}$ which was acceptable (kappa value $=0.78$ ).

Considering that the third metacarpal and the capitate length ratios in the present study (Figure 2 and Table 2) and those of the other studies $(8,9)$, follow a linear relationship and a meaningful regression formula, the current study defined a new index called capitate-index. Capitate-index was calculated from dividing the capitate length by the 3rd metacarpal length. This index was also used to compare the two groups.

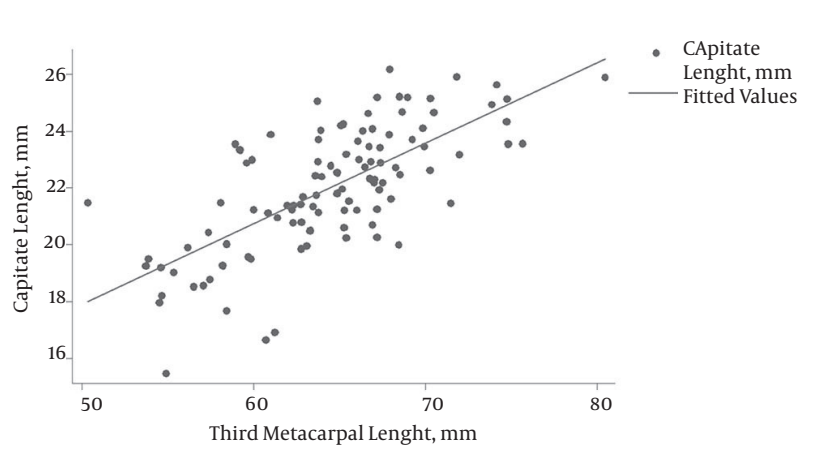

Figure 2. Linear Relationship Between the Third Metacarpal and the Capitate Length in the Control Group

\subsection{Statistical Analysis}

The variables were transferred into the computer software. The T-Student test was used to compare the means and One-way ANOVA to compare the patients with Kienböck's disease and ulnar variance $\geq 0$ and also patients with ulnar variance $<0$, with those of the control group. 
Table 1. Demographic Data of Patients and Control Group

\begin{tabular}{|c|c|c|c|c|c|}
\hline \multirow[t]{2}{*}{ Gender } & \multirow[t]{2}{*}{ Control Group $(\mathbf{n}=105)$} & \multicolumn{4}{|c|}{ Kienböck's Disease (n = 91) } \\
\hline & & Grade 2 & Grade 3a & Grade $3 b$ & Grade 4 \\
\hline Male & 63 & 17 & 21 & 22 & 4 \\
\hline Female & 42 & 5 & 11 & 10 & 1 \\
\hline Total & 105 & 22 & 32 & 32 & 5 \\
\hline
\end{tabular}

Table 2. Linear Regression Equation Between Between the Capitate Length and the Third Metacarpal Length in the Control Group

\begin{tabular}{lcccc}
\hline $\mathbf{Y}$ & $\mathbf{X}$ & PValue & $\mathbf{R}^{2}$ & Linear Regression Equation \\
\hline Capitate length & Metacarpal length & $<0.001$ & 0.49 & $\mathrm{Y}=3.72+0.28 \mathrm{X}$ \\
\hline
\end{tabular}

A P-value less than 0.05 was considered statistically significant.

\section{Results}

Measurements were performed on the wrist PAX-rays of 91 patients with KD and those of 105 individuals selected as a control group. The means of the capitate length, the third metacarpal length, the capitate-index, and the ulnar variance values were compared in both groups.

According to Table 3, no significant statistical difference was found between the patients and the control group in terms of the third metacarpal and capitate lengths. Also, there was no meaningful difference between the two groups regarding the capitate-index. The only significant difference was the negative ulnar variance in the Kienböck's group.

Table 3. Comparing Measured Parameters

\begin{tabular}{|c|c|c|c|}
\hline Variable & $\begin{array}{c}\text { Control Group (n } \\
=105)(\text { Mean } \pm \\
\text { SD) }\end{array}$ & $\begin{array}{l}\text { Kienböck }(\mathbf{n}=91) \\
\quad(\text { Mean } \pm \text { SD })\end{array}$ & P Value \\
\hline Capitate length & $22(2.21)$ & $21.94(1.65)$ & 0.83 \\
\hline $\begin{array}{l}\text { Metacarpal } \\
\text { length }\end{array}$ & $64.50(5.46)$ & $64.40(5.42)$ & 0.89 \\
\hline Ulnar variance & $0.26(0.85)$ & $-1.26(1.47)$ & $<0.001^{\mathrm{a}}$ \\
\hline Capitate-index & $0.34(0.03)$ & $0.34(0.02)$ & 0.99 \\
\hline
\end{tabular}

As illustrated in Table 4, there was no meaningful difference between the control group and the two groups of patients with ulnar variance $\geq 0$ and ulnar variance $<0$ in terms of the performed measurements.

\section{Discussion}

There was no consensus regarding the etiology of KD. Since 1928 that Hulten published his classic study on relationship between ulnar variance and KD (14), the lunate overload in ulnar minus cases were the most popular theory in this context $(15,16)$. However this theory was questioned by D'Hoore et al. reviewing 52 patients with KD. They found no significant statistical relationship between ulnar variance and $\mathrm{KD}(17)$.

Others studied the intraosseous pressure of the lunate with wrist motion and found greater pressure by $40 \mathrm{~mm}$ $\mathrm{Hg}$ in wrist extension that might be a risk factor for KD (18).

Other investigators found that the radial slope and radial inclination had a significant effect on transmitted force to the lunate (19).

Following these lunate overloading theories as mentioned above, the authors proposed the possibility of a relationship between an increased length of the capitate and the third metacarpal bones and the KD, which if proven, would justify the static and dynamic pressures on the lunate.

This idea arises from the studies that show the greater the capitate and the third metacarpal lengths, the stronger the grip strength (8). Thus, there is a possibility that increasing the third metacarpal and capitate lengths lead to an increase in static or dynamic pressures imposed by the 3 rd ray on the lunate and vulnerability to KD. Although the capitate shortening procedures recommended in the joint level or ulnar plus patients (20-24), there was no study investigating whether the capitate length of these patients was greater than those of normal individuals or not.

However, the current study could not find any significant differences between patients and the control group regarding capitate or 3rd metacarpal lengths. The only significant difference was the negative ulnar variance in the patients group; similar to many other studies. 
Table 4. Comparing the Control Group and Patients with Ulnar Variances

\begin{tabular}{|c|c|c|c|c|}
\hline & Control Group $($ Mean \pm SD $)$ & $\begin{array}{c}\text { Kienböck }(\text { Ulnar Variance } \geq 0) 33 \text { cases }= \\
\% 36(\text { Mean } \pm \text { SD })\end{array}$ & $\begin{array}{c}\text { Kienböck }(\text { Ulnar Variance }<0) 58 \text { cases }= \\
\% 64(\text { Mean } \pm \text { SD })\end{array}$ & PValue \\
\hline Capitate length & $21.944( \pm 2.192)$ & $21.993( \pm 1.481)$ & $21.948( \pm 1.779)$ & 0.99 (N.S) \\
\hline Metacarpal length & $64.403( \pm 5.430)$ & $64.036( \pm 5.089)$ & $64.598( \pm 5.868)$ & 0.90 (N.S) \\
\hline Capitate-index & $0.341( \pm 0.025)$ & $0.344( \pm 0.021)$ & $0.340( \pm 0.021)$ & 0.26 (N.S) \\
\hline
\end{tabular}

Abbreviation: N.S, Non-significant.

Given that lunate overload does not show all aspects of $\mathrm{KD}$; perhaps it is time to focus more on the biological factors such as vascular factors which are not directly related to trauma or over pressure on the lunate (25).

However, defining more meticulous reference points to measure the third metacarpal and capitate lengths is one of the strengths of the present study which was not noticed previously in normal wrist anatomic and radiologic studies (8-13).

Although these new reference points were checked in a pilot study and acceptable intraobserver reliability was observed, considering its importance in carpal height ratio and other wrist measurements; it is essential to investigate larger samples and make sure about both interobserver and intraobserver reliability of these parameters.

\section{Acknowledgments}

The authors thank Dr. Marjan Zohourian for language editing of the manuscript. Authors also wish to thank Dr. Doosti for help on statistical analysis and valuable advice.

\section{Footnote}

Authors' Contribution: Study design: Davod Jafari; manuscript writing: Hooman Shariatzadeh and Ali Ajvadi; data analysis: Ali Ajvadi; critical revision: Davod Jafari, Hooman Shariatzadeh and Ali Ajvadi; study supervision: Davod Jafari.

\section{References}

1. Innes L, Strauch RJ. Systematic review of the treatment of Kienbock's disease in its early and late stages. J Hand Surg Am. 2010;35(5):713-7. doi: 10.1016/j.jhsa.2010.02.002. [PubMed: 20438990] 717 e1-4.

2. Stahl S, Stahl AS, Meisner C, Rahmanian-Schwarz A, Schaller HE, Lotter O. A systematic review of the etiopathogenesis of Kienbock's disease and a critical appraisal of its recognition as an occupational disease related to hand-arm vibration. BMC Musculoskelet Disord. 2012;13:225. doi:10.1186/1471-2474-13-225. [PubMed: 23171057].

3. Stahl S, Stahl AS, Meisner C, Hentschel PJ, Valina S, Luz O, et al. Critical analysis of causality between negative ulnar variance and Kienböck's disease. Plast Reconstr Surg. 2013;132(4):899-909. doi: 10.1097/PRS.ob013e31829f4a2c. [PubMed: 24076682].
4. Chung KC, Spilson MS, Kim MH. Is negative ulnar variance a risk factor for Kienbock's disease? A meta-analysis. Ann Plast Surg. 2001;47(5):494-9. [PubMed: 11716259].

5. Saunders BM, Lichtman D. A classification-based treatment algorithm for Kienböck's disease : current and future considerations. Tech Hand Up Extrem Surg. 2011;15(1):38-40. doi: 10.1097/BTH.0b013e31820e82d2. [PubMed: 21358524].

6. Schreibman KL, Freeland A, Gilula LA, Yin Y. Imaging of the hand and wrist. Orthop Clin North Am. 1997;28(4):537-82. [PubMed: 9257964].

7. Palmer AK, Glisson RR, Werner FW. Ulnar variance determination. $J$ Hand Surg Am. 1982;7(4):376-9. [PubMed: 7119397].

8. Schuind FA, Linscheid RL, An KN, Chao EY. A normal data base of posteroanterior roentgenographic measurements of the wrist.JBone Joint Surg Am. 1992;74(9):1418-29. [PubMed: 1429800].

9. Mohammed Ali MH. A normal data-base of posteroanterior radiographic measurements of the wrist in healthy Egyptians. Surg Radiol Anat. 2009;31(9):665-74. doi: 10.1007/s00276-009-0500-4. [PubMed: 19352583].

10. Jafari D, Taheri H, Shariatzade H, Mazhar FN, Jalili A, Ghahramani M. Radiographic indices in one hundred fifty normal Iranian wrists. Med J Islam Repub Iran. 2012;26(3):132-9. [PubMed: 23482869].

11. Nattrass GR, King GJ, McMurtry RY, Brant RF. An alternative method for determination of the carpal height ratio. J Bone Joint Surg Am. 1994;76(1):88-94. [PubMed: 8288669].

12. Wang YC, Tseng YC, Chang HY, Wang YJ, Chen CJ, Wu DY. Gender differences in carpal height ratio in a taiwanese population.J Hand Surg Am. 2010;35(2):252-5. doi: 10.1016/j.jhsa.2009.11.010. [PubMed: 20141895].

13. Stahelin A, Pfeiffer K, Sennwald G, Segmuller G. Determining carpal collapse. An improved method. J Bone Joint Surg Am. 1989;71(9):14005. [PubMed: 2793895].

14. Hulten O. Uber die entstehung und behandlung der lunatummalaziemorbuskienbock. 76. Act Chir Scand;1928. p. 121.

15. Lamas C, Carrera A, Proubasta I, Llusa M, Majo J, Mir X. The anatomy and vascularity of the lunate: considerations applied to Kienbock's disease. Chir Main. 2007;26(1):13-20. doi: 10.1016/j.main.2007.01.001. [PubMed: 17418764].

16. Irisarri C. [Aetiology of Kienbock's Disease]. Handchir Mikrochir Plast Chir. 2010;42(3):157-61. doi: 10.1055/s-0030-1253394. [PubMed: 20552544].

17. D’Hoore K, De Smet L, Verellen K, Vral J, Fabry G. Negative ulnar variance is not a risk factor for Kienbock's disease. J Hand Surg Am. 1994;19(2):229-31. doi: 10.1016/0363-5023(94)90010-8. [PubMed: 8201185].

18. Schiltenwolf M, Martini AK, Mau HC, Eversheim S, Brocai DR, Jensen $\mathrm{CH}$. Further investigations of the intraosseous pressure characteristics in necrotic lunates (Kienbock's disease). J Hand Surg Am. 1996;21(5):754-8. doi: 10.1016/S0363-5023(96)80187-0. [PubMed: 8891969].

19. Tsuge S, Nakamura R. Anatomical risk factors for Kienbock's disease. $J$ Hand Surg Br. 1993;18(1):70-5. [PubMed: 8436868]. 
20. Waitayawinyu T, Chin SH, Luria S, Trumble TE. Capitate shortening osteotomy with vascularized bone grafting for the treatment of Kienbock's disease in the ulnar positive wrist. J Hand Surg Am. 2008;33(8):1267-73. doi: 10.1016/j.jhsa.2008.04.006. [PubMed: 18929187].

21. Citlak A, Akgun U, Bulut T, Tahta M, Dirim Mete B, Sener M. Partial capitate shortening for Kienbock's disease. J Hand Surg Eur Vol. 2015;40(9):957-60. doi: 10.1177/1753193414562355. [PubMed: 25432157].

22. Moritomo $\mathrm{H}$, Murase $\mathrm{T}$, Yoshikawa $\mathrm{H}$. Operative technique of a new decompression procedure for Kienböck's disease : partial capitate shortening. Tech Hand Up Extrem Surg. 2004;8(2):110-5. doi 10.1097/01.bth.0000126571.20944.47. [PubMed: 16518122].
23. Gay AM, Parratte S, Glard Y, Mutaftschiev N, Legre R. Isolated capitate shortening osteotomy for the early stage of Kienböck's disease with neutral ulnar variance. Plast Reconstr Surg. 2009;124(2):560-6. doi: 10.1097/PRS.ob013e3181addc50. [PubMed: 19644275].

24. Afshar A, Mehdizadeh M, Khalkhali H. Short-Term Clinical Outcomes of Radial Shortening Osteotomy and Capitates Shortening Osteotomy in Kienböck's disease. Arch Bone Jt Surg. 2015;3(3):173-8. [PubMed: 26213706].

25. Gelberman RH, Bauman TD, Menon J, Akeson WH. The vascularity of the lunate bone and Kienbock's disease.JHand Surg Am. 1980;5(3):2728. [PubMed: 7400565]. 